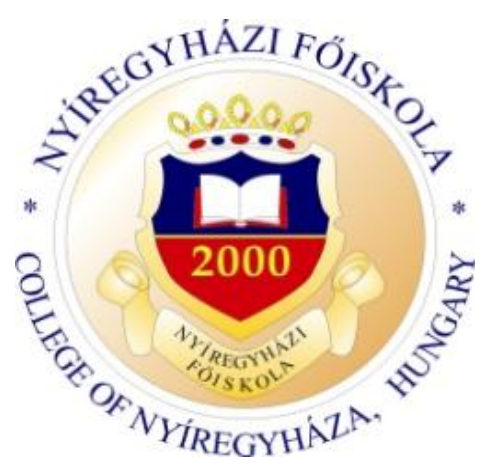

\title{
Metaphors in Everyday English
}

\author{
Torda Gábor \\ Anglisztika
}

Konzulens: Dr. Ajtay-Horváth Magda PhD

2014 


\begin{abstract}
The present paper shows the development of the concept of metaphor since Aristotle's first definition until the interpretations provided by cognitive linguists in the second half of the $20^{\text {th }}$ century. In the ancient philosophies metaphor was considered an ornamental device, appropriate for poetry only. This classical view radically changed in the twentieth century and since then numerous conceptualizations have been proposed to reinvent the notion of metaphor. Recent studies in cognitive science by Zoltán Kövecses and George Lakoff have shown that metaphors are a fundamental part of human cognition. Their dynamic structure helps us to better understand abstract scientific concepts, trigger emotions, and enrich our everyday language. This work provides an overview of the process of metaphor comprehension through various theories. Furthermore, by applying the method of comparison, I analyse some conventional English metaphors and their Hungarian counterparts in support of the idea that metaphor is omnipresent in our everyday language; however, their mapping can be influenced by cultural factors.
\end{abstract}




\section{Table of Contents}

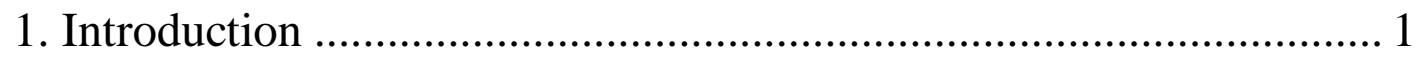

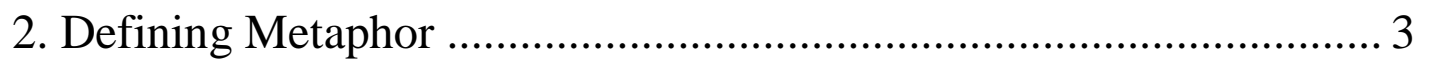

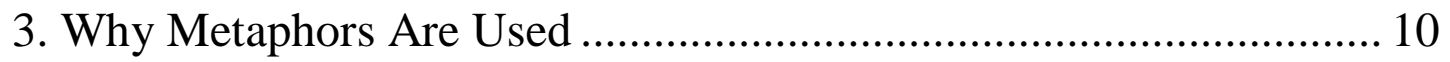

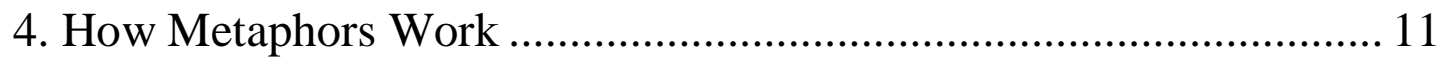

4.1 What Is Considered Metaphoric ..................................................................... 12

4.2 The Problem of Metaphor Comprehension ..................................................... 13

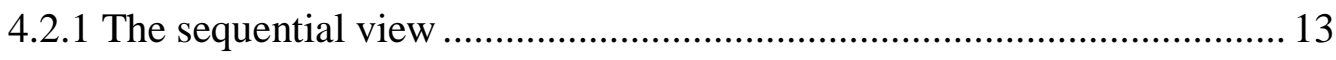

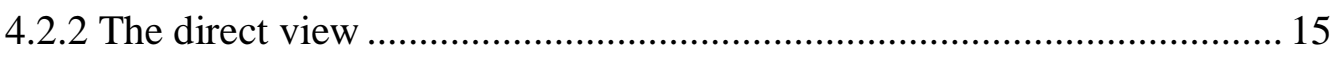

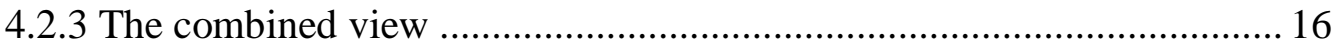

4.3 The Problem of Asymmetry in Metaphors ………………………………..... 18

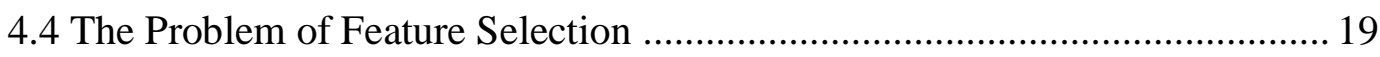

5. Contemporary Models of Metaphor ….............................................. 21

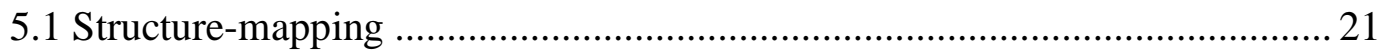

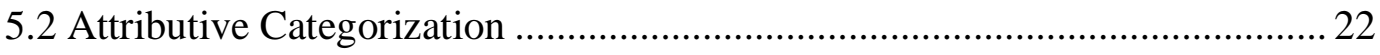

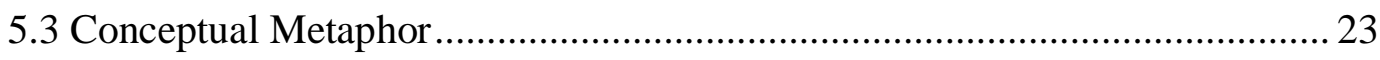

6. Comparison of English and Hungarian Metaphors ........................... 27

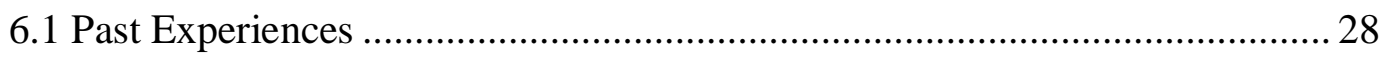

6.2 Source-target Mapping Variations ................................................................... 30

6.3 Language Peculiarities ................................................................................ 31

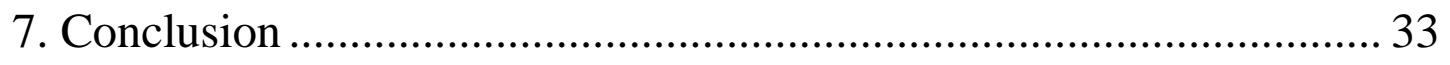

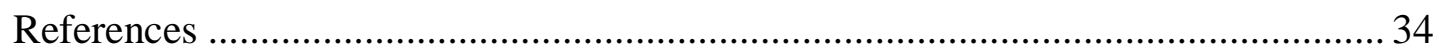




\section{Introduction}

Throughout centuries metaphor has been considered a privileged, secondary type of language, accessible only to poets, writers and other creative people. This view, first advocated by Aristotle, was dominant up until the early 1900s. Metaphors are frequently used in literature, for instance in Shakespeare's famous lines:

All the world's a stage,

And all the men and women merely players.

They have their exits and their entrances,

And one man in his time plays many parts,

His acts being seven ages....

Traditional philosophical views did not treat metaphor as a central concern in the human perception of the world. However, over the last few decades studies have shown that this phenomenon is omnipresent in our everyday language, with power that goes beyond the extensive literary usage. Ordinary people think metaphorically as well. They use it every day, instantly, consciously or unconsciously, because it is pervasive in language and thought. This revolutionary theory of meaning within the fields of linguistics and philosophy was formulated by George Lakoff and Mark Johnson (Lakoff \& Johnson, 1980).

This shift in the conception of metaphor has led many cognitive scientists to make advancements in creating the most comprehensive and accurate models of the metaphor. From philosophers to linguists, everyone agrees that people must understand not only literary meanings, but a speaker's intended meanings as well. The difference lies in the interpretation of the various models of metaphor.

This work is dedicated to presenting the primary models of metaphor 
comprehension —-from a philosophical and linguistic perspective-in support of the thesis that metaphor is omnipresent in our everyday language. Following the theories, I will analyze some common English metaphors and their Hungarian counterparts according to cognitive views in a contrastive manner. 


\section{Defining Metaphor}

Metaphor is a fundamental part of language and apparently as old as language itself. It can be found in one of the earliest surviving works of literature, The Epic of Gilgamesh. While the ancient Romans emphasized the importance of similes, the Greeks preferred using metaphors. The English word comes from the Greek metapherein, meaning to transfer (Oxford Dictionaries, n.d.). According to some rhetoricians, metaphor is one of the master tropes, alongside metonymy, synecdoche and irony.

Since antiquity, metaphor has been the most researched trope, and for this reason several theories have been constructed that date back to the early times. The first and narrow definition is attributed to Aristotle. He discusses the relationship of metaphor and language and the role of the former in communication primarily in two of his works, Poetics and Rhetoric. His definition is the following in Poetics: "Metaphor consists in giving the thing a name that belongs to something else" (Aristotle, trans. 2009, XXI). Aristotle classifies metaphor as an implicit comparison, a property of language, which is discussed in terms of a noun. According to his views there are eight kinds of nouns: the ordinary word, the strange word, the metaphor, the ornamental word, the coined word, the lengthened-out word, the curtailed word and the form-altered word. His early definition considered metaphor as a privileged use of words, only accessible to creative people, and nonexistent in everyday language. He summarizes this sentiment as follows: "[T]he greatest thing by far is to be a master of metaphor. It is the one thing that cannot be learnt from others; and it is also a sign of genius, since a good metaphor implies an intuitive perception of the similarity in dissimilars" (Aristotle, trans. 2009, XXI).

Until the development of contemporary views on metaphor comprehension, rhetoric had been the basic field of enquiry for scholars. As a consequence, any serious 
study of the subject almost required citing the works of Aristotle. This focus on rhetoric had been the dominant view for over two millennia.

The turning point came in 1936, when Ivor Armstrong Richards published The Philosophy of Rhetoric, influencing contemporary theoretical studies. His work breaks away from the traditional, ornamental theory, which governs only the lexical level of metaphors and concerns the whole text on an abstract semantic level. He rejects Aristotle's beliefs and argues that it is not a sign of genius to comprehend and use metaphors. According to Richards, metaphoric thinking does not require any special knowledge: "That metaphor is the omnipresent principle of language can be shown by mere observation. We cannot get through three sentences of ordinary fluid discourse without it ..." (Richards, 1936, p. 92).

He introduced the basic terminology of the two parts of a metaphor, the tenor and the vehicle. The tenor is the subject to which the attributes are transferred. The vehicle is the object whose attributes are borrowed. The common characteristic is called the ground of the metaphor. To illustrate this he gives the classic example of the leg-of-the-table metaphor: In this case the vehicle is the human leg, and the table is the tenor. However, a table does not walk with its legs. The legs only hold it up. In such a case we can talk about common characteristics.

Prior to Richards there had been no distinguishing terms for these two halves of a metaphor. However, the following phrases had been used to convey a similar meaning: "The original idea and the borrowed one; what is really being said or thought of and what it is compared to; the underlying idea and the imagined nature; the principal subject and what it resembles" (Richards, 1936, p. 96). The other important aspect of his work is its prompting of the development of the interaction view, that is, the semantic interaction between the tenor and vehicle. It means: "when we use a metaphor we have two thoughts 
of different things active together and supported by a single word, or phrase, whose meaning is a resultant of their interaction" (Richards, 1936, p. 93). Richards gave a cognitive value to metaphors and thus influenced a new generation of theorists, among them the philosopher Max Black, who put forward the interaction view of metaphor. Richards's insights form the basis of Black's interaction theory.

Black discusses mainly three views of metaphor: substitution, comparison and interaction. He considers the comparison view a special case of the substitution view. "[T]he substitution view regards the entire sentence that is the locus of the metaphor as replacing some set of literal sentences; while the comparison view takes the imputed literal paraphrase to be a statement of some similarity or analogy, and so takes every metaphor to be a condensed or elliptic simile" (Black, 1993, p. 27).

Out of the three views, Black's interaction theory is the most influential, and the only one Black himself accepts. He wanted to break away from the previous oversimplified comparison-based, traditional accounts of metaphor, which considered metaphors as elliptic similes. The interaction view claims that metaphor does not work at the level of word combination, as posited by the previous comparison-based Aristotelian view, but rather at a deeper level, composed out of the interactions between the conceptual structures. The emphasis is on the interaction between systems rather than upon things and ideas, as in Richards's view.

Black argues that a metaphorical statement has two distinct subjects, a principal and subsidiary subject (Black, 1993, p. 27). The cognitive content is the result of their interaction, and the common ground is what he calls "the system of associated commonplaces."

He introduces another pair of terms as well, the constituents of the metaphorical utterance: the metaphorical focus and the literal frame. Compared to Richards's tenor and 
vehicle, in this case two sets of terms are needed and there exists a dynamic correlation between the subjects and the two poles of the metaphorical utterance. They can be interchangeable. In his work, Black focuses on a particular type of metaphor, where the principal subject coincides with the frame (Black, 1954, p. 286). It happens in the case of a metaphorical definition of a subject, where the focus is a predicate noun. An example is the classic Man is a wolf metaphor: Here, the principal subject, Man, coincides with the frame and interacts with the subsidiary subject, wolf, which coincides with the focus. Black argues that Man is seen through wolf and uses the metaphor of a screen. Construing the meaning of this metaphor, language users apply the conventional knowledge associated with wolves to serve as the "smoked glass" through which they see men.

"Suppose I look at the night sky through a piece of heavily smoked glass on which certain lines have been left clear," Black (1954) writes.

Then I shall see only the stars that can be made to lie on the lines previously prepared upon the screen, and the stars I do see will be seen as organized by the screen's structure. We can think of a metaphor as such a screen and the system of "associated commonplaces" of the focal word as the network of lines upon the screen. We can say that the principal subject is "seen through" the metaphorical expression or, if we prefer, that the principal subject is "projected upon" the field of the subsidiary subject. (p. 286)

The rhetorician I. A. Richards heavily influenced Black, but the most important merit of Black's work is that he rediscovered metaphor for philosophy.

There are radical theories as well (though these are not to be confused with the Radical Metaphor theory developed by W. M. Urban, whose analysis of meaning resulted in his discovery that "a second stage of language is developed which is metaphorical in its 
nature. This second stage contains the fundamental method of natural speech construction”) (Shibles, 1971, p. 27). Donald Davidson takes a radical twist and denies that metaphors have any second or metaphorical meaning: "[M]etaphors mean what the words, in their most literal interpretation, mean, and nothing more" (Davidson, 1984, p. 245). He is against the semantic interpretation of a metaphor, especially the one formulated by Black. For him metaphor is a perlocutionary act that cannot be explained within semantics or pragmatics.

The pragmatic study of metaphor has been heavily influenced by John Searle, who studies metaphor as part of the speech act. He sees metaphorical utterances as indirect speech acts. His pragmatic inference is the following: "To have a brief way of distinguishing what a speaker means by uttering words, sentences, and expressions, on the one hand, and what the words, sentences, and expressions mean, on the other, I shall call the former speaker's utterance meaning, and the latter, word, or sentence meaning. Metaphorical meaning is always speaker's utterance meaning” (Searle, 1979, p. 84). Similar to Davidson, Searle denies metaphorical sentence meaning. On the other hand, he argues that metaphorical utterance meaning is genuinely a part of linguistic communication. By formulating the problem of metaphor comprehension, Searle (1979) investigated the following main questions in a landmark article: "How do metaphorical utterances work, that is, how is it possible for speakers to communicate to hearers when speaking metaphorically inasmuch as they do not say what they mean? And why do some metaphors work and others not?” (p. 83). The chapter in this thesis dealing with metaphor theories will cover these questions as well.

The pragmatic view of metaphor has become very influential in the field of psycholinguistic research. From Aristotle's first definition through Searle's speech act theory, metaphor has been viewed entirely differently. However, many questions remain 
open and many of the answers have come in the form of cognitive scientific views of metaphors. Since the 1970s, cognitive linguists and psychologists have been fully aware that metaphors are not only a matter of words, but rather are central to thought and action and everyday language as well. All the upcoming models and hypotheses have been influenced by Max Black, and Richards indirectly. Further research in the field has centered on the following three major issues:

- Stages of metaphor comprehension

- Asymmetry in metaphors

- Feature selection

To solve these controversies, the new cognitive interpretation has led to the formation of various theories, hypotheses and models of metaphor over the last few decades. One of them is Ortony's salience imbalance model. He uses the notion of salience to solve feature selection and the asymmetry in metaphors. The essence of this model is that metaphors are comprehended in terms of shared features. There are particular comparison pairs between tenor and vehicle. Out of the four possible variations, only the low-high combinations typify metaphoric comparisons. An example is the following sentence: John's face was like a beet. The simile involves a match between features that is not salient in the subject, John, but salient in the predicate, redness (Ortony, 1993, p. 417). This model is a step forward to creating an accurate model of metaphorical mapping, but lacks an explanation of how features are selected in the comparison.

After the salience imbalance theory we can consider three fundamental theories of metaphor that still hold their own today. One of them is the structure-mapping model formulated by the psychologist Dedre Gentner. Her model treats metaphor as an instance 
of analogy, based on the comparison view. Glucksberg and Keysar developed their model based on categorization; it is called the attributive categorization model. The third widely acknowledged cognitive theory is Lakoff's conceptual metaphor theory.

There have been various other interpretations but the last three are the most influential and viable in the fields of cognitive linguistics and psychology. The focus of my paper is Lakoff's conceptual theory because his work was the first to explicitly state that metaphors are pervasive in thought, action and everyday language as well. 


\section{Why Metaphors Are Used}

There are many ways to experience the world and metaphors play an important role in all of them. Metaphoricity is a universal process. It happens in all languages and at all levels. They help us to better understand abstract scientific concepts, trigger emotions, and enrich our everyday language. According to Black, "Metaphors are generally used to describe something new by reference to something familiar" (Ortony, 1993, p. 420). As Ortony argued, "Metaphors are not just nice, they are necessary" (Ortony, 1993, p. 420). He formulated three hypotheses regarding why people use metaphors. The first suggests the direct and compact form of a metaphor can capture the essence of a particular experience. The second, the inexpressibility hypothesis, emphasizes that metaphors allow us to express ideas that are difficult or even impossible to express in literal language. The third points to the role of metaphor as a tool for presenting ideas through vivid images more memorably than literal language can allow. 


\section{How Metaphors Work}

Aristotle considered metaphor as indicative of genius, ornamental, appropriate for poetry only, and too puzzling for philosophical or scientific discourse. According to his comparison view, in which $\mathrm{X}$ is $\mathrm{Y}$, metaphors are understood by implicitly converting them into elliptical similes. This classical view was replaced in the twentieth century and since then numerous conceptualizations have been proposed to reinvent the notion of metaphor.

In contrast to Aristotle's view, recent studies in cognitive science have shown (Lakoff \& Johnson, 1980) that Metaphors are a fundamental part of human cognition. Metaphors are able to process large amounts of information automatically and they can also be used to communicate abstract scientific ideas. Contemporary cognitive linguists believe that cognition is built up from concrete to abstract, and concrete domains function as source domains for metaphorical processes involved in creating abstract domains. On the other hand, cross-cultural researchers and anthropologists document the metaphors language users actually use. These researches reflect the way in which people use language according to different cultural backgrounds.

During the process of rethinking the classical view several questions have been left unanswered: What, for instance, is metaphoric? And how do we perceive metaphors? In the following chapters I will evaluate these central problems in metaphor comprehension. 


\subsection{What Is Considered Metaphoric}

In order to define what is metaphoric, it is first helpful to contrast it with what is not. The most important merit of Searle's account of metaphor is that it defines this contrast by characterizing literal meaning. If we did not have an account of literal meaning, then metaphorical utterance meaning would not say much. "[I]n literal utterance the speaker means what he says; that is, literal sentence meaning and speaker's utterance meaning are the same" (Ortony, 1993, p. 87). As I have mentioned, according to Searle, metaphorical meaning is always speaker's utterance meaning, the conveyed meaning. So the general problem is to distinguish between the speaker's utterance meaning and literal sentence meaning.

Searle summarizes some aspects of literal utterances. First, in a literal utterance the speaker means what he says. Second, literal meaning is context-free and can only be determined relative to a set of background assumptions. To give an example, the sentence The cat is on the mat can only be interpreted as literal if we have some background assumptions, e.g. the cat and the mat are not floating in space and gravitational forces exist. However, in a more recent work Searle (1983) argued that literal meaning is not context-free and it is impossible to list all of the background assumptions (p. 145). Third, the notion of similarity plays an essential role in any account of literal predication.

Glucksberg (1998), the developer of the attributive categorization theory, argues similarly to Searle by stating:

In figurative language, the intended meaning does not coincide with the literal meanings of the words and sentences that are used. Because literal and figurative meanings do not coincide, figurative language has traditionally been considered derivative from and more complex than ostensibly straightforward literal 
language. (p. 39)

Before Searle, authors had taken literal meaning so much for granted that they assumed everyone knew how it worked. This led to descriptions of metaphorical utterances that failed to distinguish them from literal ones.

In recent years, the development of cognitive sciences has proved the traditional literal-metaphorical assumptions to be false. Searle's traditional account of metaphor comprehension starts from the literal interpretation, and when a sentence does not make sense literally, then and only then comes the metaphoric stage. The contemporary view is the opposite. Those concepts not comprehended via the system of conceptual metaphor might be called literal.

\subsection{The Problem of Metaphor Comprehension}

The contemporary cognitive view of metaphor is intended to account for common, everyday uses of metaphor. It is also important to note that metaphors are omnipresent not just in everyday language but also in numerous academic disciplines. As a result of these realizations various studies have been conducted to deal with different aspects of metaphor comprehension. The most important question is: How do we perceive metaphors in comparison to literal statements? There are three different basic theories of language processing. These are the sequential, the direct, and the combined views.

\subsubsection{The sequential view}

Traditional theories of metaphor were mainly two- or three-process theories. It was believed that a metaphor demands greater cognitive skills to be understood than 
literal sentences. According to the pragmatic theory, people first look for the literal meaning of an utterance. The next step is to determine whether the literal meaning makes sense in the context. If it does not make sense in context, then the non-literal interpretation process is initiated (Searle, 1979, p. 84). In pragmatic views, understanding metaphors such as Encyclopedias are gold mines requires going beyond the literal. Encyclopedias are not holes in mountains where gold can be found, so this sentence cannot be understood directly. Instead, metaphors are implicitly converted to comparison statements such as Encyclopedias are like gold mines and then interpreted literally.

The standard pragmatic view has three fundamental implications. First, the literal interpretation has unconditional priority because literal meanings are always computed before any figurative meanings, and the latter involves a sequential process. The second implication is that metaphor understanding is optional. If the literal meaning of a sentence does make sense in a given context, people will not go beyond the literal meaning. Finally, the ground of a metaphor is the result of an implicit comparison (Glucksberg, 1998, p. 39).

However, this view was proven to be incorrect by a revealing experiment. In their research Glucksberg, Gildea and Bookin (1982) showed that such implications are false. Metaphor understanding is not optional and is processed as quickly and automatically as literal language, and metaphors are understood directly, not via an implicit comparison (Glucksberg et al., 1982).

Their metaphor interference technique offers a way to detect early processes in metaphor comprehension. In the experiment, participants were shown three kinds of statements: class-inclusion statements that are true (e.g. Some birds are robins), false class-inclusion statements (e.g. Some birds are apples) and metaphorical statements (e.g. 
Some jobs are jails). The listeners were asked to judge whether the statements were literally true or false. As expected, participants could quickly classify literally true statements as true, and false statements as false. However, they were significantly slower rating metaphors as literally false. The conclusion was that participants interpreted the metaphorical statements automatically and metaphorically. Therefore the subsequent literal interpretation in turn required more processing time. The results proved the twoand three-process theories false. According to these theories, a statement must be interpreted literally first, and if it does not make sense in the context, an alternative figurative interpretation process is initiated. This metaphor interference technique was a strong evidence for the early metaphor comprehension.

\subsubsection{The direct view}

The indirect processing conception has been replaced by the direct (parallel) view, one of the contemporary views of metaphor comprehension. It has the following main implications: Understanding metaphor is identical to understanding literal language, and it does not involve a special process or a greater effort. Literal language has no priority over non-literal language. Figurative language can be processed directly, without having to activate the literal meaning first (Giora, 1997).

The classic experiment of Glucksberg, Gildea, and Bookin was the first significant step towards the direct process model. Other empirical studies have been conducted in this field as well by Keysar (1989), Gibbs (1984), or Coulson and Van Petten (2002).

According to the traditional theories (Searle, 1979), metaphor interpretation requires a triggering condition, such as a violation of a discourse rule. Keysar (1989) argues that rule violation is not a necessary condition; metaphoric meaning is activated 
automatically, independently of any trigger. Gibb's direct access view suggests that listeners need not automatically analyze the complete literal meanings of linguistic expressions before accessing pragmatic knowledge to figure out what speakers mean to communicate (Gibbs, 2002, p. 460). He argues that metaphor comprehension requires the same processes as literal language comprehension.

In Coulson and Van Petten's (2002) experiment, event-related brain potentials (ERPs) were recorded from adults as they read sentences that ended with words used literally, metaphorically, or in an intermediate literal mapping condition. The authors compared the continuity claim (that literal and non-literal language processing occur in the same time course and involve the same processing mechanisms) and the equivalence claim (that metaphoric language is no more difficult to comprehend than literal language). Their findings were consistent with the continuity claim and revealed that literal and metaphoric languages share some processing mechanisms, but inconsistent with the equivalence claim that comprehension of metaphoric language is no more difficult than literal language. In their opinion, greater cognitive efforts are needed for metaphor comprehension but literal and figurative interpretation requires the same amount of time (Coulson \& Van Petten, 2002).

\subsubsection{The combined view}

The indirect (sequential) and the direct (parallel) views are the two contrasting theories. However, there are other views that make a variation out of them. The most influential is the combined view, which propagates the graded salience hypothesis. It was developed by Rachel Giora (1997), who argues that metaphor comprehension may involve different processes according to the type of metaphors involved (novel or 
conventional). Previously, in most empirical studies that had supported the direct view, only conventional, everyday metaphors had been used. Those studies set aside novel metaphors; therefore their results can be questioned.

Giora emphasizes the importance of salience (i.e. conventionality, familiarity, frequency), which governs literal and non-literal language use. Ortony's salience imbalance theory is similar with respect to using salient properties. If a word has two meanings, the more conventional, popular or frequently used meaning is the most salient.

According to this theory, instead of the literal-metaphoric split, the salient-nonsalient division is what matters. The graded salience hypothesis posits that the salient meanings should be processed first, independent of the given context. Less-salient (novel) metaphor understanding requires a sequential process, whereby the more salient (literal) meaning is processed first. Furthermore, novel interpretation must be more difficult to derive. Novel metaphors such as "Her wedding ring is a 'sorry we're closed' sign" are non-salient, and are slowed in processing due to having to reject the literal meaning of the phrase first. On the other hand, conventional metaphors, whose literal and metaphoric interpretations are equally salient, require parallel processing (Giora, 1997).

Bowdle and Gentner (2005) also support these claims. According to them, both direct or indirect metaphor comprehension is possible. Thus, conventional metaphors are usually understood by direct categorizations, and conventional similes are often processed as direct comparisons. For novel metaphors, comprehension may be either direct or indirect depending on grammatical form. Whereas novel similes are processed as direct comparisons, novel metaphors are processed as indirect comparisons. Additionally, a conventional metaphor will require less cognitive effort than a novel type for mappings between a target and a metaphor category, resulting in easier interpretation and faster processing of conventional metaphors (Bowdle \& Gentner, 2005). The reason for this, 
according to Bowdle and Gentner (2005), is that

[C]onventional metaphoric categories will contain fewer predicates than the literal concepts they were derived from, and a higher proportion of these predicates can be mapped to relevant target concepts. Therefore, aligning a target with a metaphoric category will be computationally less costly than aligning a target with a literal base concept. (p. 211)

\subsection{The Problem of Asymmetry in Metaphors}

Another phenomenon related to metaphors is asymmetry. In a metaphoric phrase, the use of a vehicle affects the tenor in some way. The information is directionally projected from the vehicle to the tenor. In a nominal metaphor such as This job is a jail, ideas like discipline that are associated with the vehicle, jail, are projected to the tenor, job. However, the transfer in the reverse direction-This jail is a job-does not impart the same message, and often leads to a meaningless phrase or a change in meaning. For example, My surgeon is a butcher implies he or she is clumsy; on the other hand, My butcher is a surgeon implies cutting precisely. This inherent asymmetry in metaphors is addressed differently by the two basic metaphor-processing models. The processing, also called mapping, can be based on the model of comparison or categorization.

Ortony considered this asymmetry a distinctive feature of metaphoricity in his

salience imbalance theory (Ortony, 1979, p. 179). He argues that nonliteral similarity statements will tend to be much less reversible than literal similarity statements. According to him, metaphors are directionally asymmetric. However asymmetries also occur in literal similarity statements as well. Eleanor Rosch (1973), known for her work on categorization, was able to demonstrate directional preferences based on her prototype 
theory. In her experiment, out of the two alternatives "Pink is virtually red" was preferred to "Red is virtually pink." This evidence proves that asymmetry is not specific to metaphors (Rosch, 1973).

To conclude, unidirectionality or asymmetry seems to be a necessary element for metaphorical mappings. The only question is where in the mapping this asymmetry appears in the various contemporary models of metaphor. It is also important to note that reverse or bidirectional metaphors do exist, although they are not regular in contemporary metaphor studies.

\subsection{The Problem of Feature Selection}

The last key concept in all metaphor theories is feature selection. Tenor and vehicle share many of the same features. The question is: How are only a few of many shared features selected in metaphor creation and others are not? To return to a previous example, butchers and surgeons have much more in common than just how precise they are. For instance, they both usually wear white and have an occupation, among many other features.

In Ortony's salience imbalance model metaphors are comprehended in terms of shared features. Out of the four possible variations, only the low-high combinations typify metaphoric comparisons. Unlike similarities, which typify a high-high match, in metaphors the shared features are of high salience in the vehicle, but of low salience in the tenor. Therefore not every shared feature of the tenor and the vehicle is included in an interpretation.

To address most of the aforementioned problems such as asymmetry or feature selection, a new wave of metaphor theories has emerged in the last few decades. The most 
influential and viable models, which still hold their accounts as of today, are the structuremapping, the attributive categorization, and the conceptual metaphor theories. 


\section{Contemporary Models of Metaphor}

Attempts to answer the problems above have come in the form of cognitive scientific views of metaphor, with typical representative fields including cognitive psychology and cognitive linguistics. "What characterizes twentieth-century philosophy is the view that language must be given careful consideration and not treated as a mere shadow of an idea or be merely something taken for granted as has usually been the case" (Shibles, 1971, p. 1).

Since the 1970s cognitive linguists and psychologists have become fully aware that metaphors are not only a matter of words, but rather are pervasive in everyday language and thought as well. The cognitive linguistic theory of metaphor was developed in George Lakoff and Mark Johnson's (1980) widely read book Metaphors We Live By, which inspired many of the studies that followed. However, their model could not successfully capture all aspects of the controversies. For instance, their conceptual metaphor theory overemphasized the universality of some of the metaphorical structures they found, and lacked in defining diversities. As a result, besides Lakoff and Johnson's conceptual metaphor theory, two contrasting models have been developed: the structuremapping and attributive categorization models. Metaphor comprehension today is usually interpreted through these three models.

\subsection{Structure-mapping}

Several empirical studies have supported the structure-mapping model of metaphor processing. Influenced by Lakoff, Gentner and her colleagues approached metaphor from a cognitive psychology perspective. Their results have confirmed that the 
structure-mapping model can interpret metaphors accurately. This model can also be used to describe novel metaphors, which had been mostly excluded from previous metaphor models (Lai, Curran \& Menn, 2009).

This model treats metaphor as a kind of analogical comparison. Metaphor involves mappings between the vehicle and the tenor. Cognitive scientists usually refer to the vehicle as the base or source, and to the tenor as the topic or target. This model is also based on a comparison view, like most of the metaphor models; however, it deploys a much more sophisticated comparison process than Black's or Ortony's models. Structuremapping describes metaphor as a directional process in which a stable, familiar base domain provides inferential structure to a less clearly specified target. But metaphor is also described as a process of finding commonalities, an inherently symmetric process. In this second view, both concepts may be altered by the metaphorical comparison. Whereas most theories of metaphor capture one of these aspects, structure-mapping captures both sides of metaphor processing. This predicts an initially role-neutral processing stage of symmetric alignment, followed by directional projection of inferences (Wolff \& Gentner, 2011). Thus, in structure-mapping, processing starts out as symmetrical and ends as directional. "This theory differs from other approaches in postulating that the interpretation rules for analogies and relational metaphors are based on predicate structure, rather than on feature salience or mental distance" (Gentner, 1986).

\subsection{Attributive Categorization}

From Aristotle to cognitive scientists, metaphor has been viewed mostly as an implicit comparison. The comparative view postulates that the source and target of a metaphor may belong to the same category. However, Glucksberg and Keysar have taken 
an almost entirely different approach to metaphor. They argue that metaphor should be considered an implicit category statement rather than a simile: "When metaphors are expressed as comparisons, that is, as similes, they are interpreted as implicit category statements, rather than the other way around" (Glucksberg \& Keysar, 1993, p. 422).

According to the concept of class-inclusion, the target of a metaphor is a member of a category defined by features, which can be represented by the source domain. For example, in the metaphor My lawyer is a shark, the target, My lawyer, is placed in the category of aggressivity of which the source, shark, is a salient representative. Although My lawyer is a shark makes sense, My shark is a lawyer does not. According to this model, the inherent asymmetry cannot be explained by the comparative view, and explaining this asymmetry was one of Glucksberg and Keysar's primary goals.

The categorization view has not been widely accepted by theorists because some degree of comparison is still necessary to decide which features represent the category into which the target is placed.

\subsection{Conceptual Metaphor}

The third significant cognitive theory of metaphor was formulated by George Lakoff and Mark Johnson. Their conceptual metaphor theory-first described in their book Metaphors We Live By (Lakoff \& Johnson, 1980)—comes out of the field of cognitive linguistics. One of the main areas of research inside cognitive linguistics is cognitive semantics. In the latter field, Lakoff and Johnson have investigated the relationship between experience, the conceptual system, and the semantic structure encoded by language. They define metaphor as mapping across conceptual domains. They were the first to explicitly state and propagate the idea that metaphors are pervasive in 
thought, action and everyday language. This phenomenon structures our perceptions and understanding of the world: "Our ordinary conceptual system, in terms of which we both think and act, is fundamentally metaphorical in nature" (Lakoff \& Johnson, 1980, p. 3).

According to this theory, most of our fundamental concepts are various kinds of metaphors:

- Orientational metaphors are related to spatial orientation (up-down, in-out, frontback, on-off, etc.). For example Happy is up, sad is down. In the English language, the concept happy is oriented up, leading to expressions like You are in high spirits. Up and high usually refer to good things in English-speaking cultures, for instance high status.

- Ontological metaphors associate activities, emotions and ideas with something concrete, such as a person or an object. For instance, the phenomenon of inflation is conceived of as an entity-e.g., We need to combat inflation. Metaphors involving personification are the most obvious examples of this type.

- Structural metaphors are based on other two types, which allow us to understand an abstract concept in terms of another sharply defined concept. The mapping is from concrete to abstract. Some examples are Rational argument is war, Labor is a resource, or Time is a resource.

Traditional theories considered metaphor as a matter a language only. For Lakoff, it is central to thought. He also makes a distinction between "metaphor" and "metaphorical expression." The former refers to cross-domain mappings in the conceptual system; the latter refers to a linguistic expression that is a surface-level realization of such a cross-domain mapping.

To describe his idea, Lakoff gives examples of conceptual metaphors like Argument is war.

This conceptual metaphor is reflected in our everyday language by a variety of 
metaphorical expressions:

- Your claims are indefensible.

- He attacked every weak point in my argument.

- His criticisms were right on target.

- I demolished his argument.

- I've never won an argument with him.

- You disagree? Okay, shoot!

- If you use that strategy, he'll wipe you out.

- He shot down all of my arguments.

In an everyday language situation there is a verbal battle, and the structure of an argument—with its constituent conceptions of attack, defense and counterattack—reflects this. "It is in this sense," argue Lakoff and Johnson (1980), "that the ARGUMENT IS WAR metaphor is one that we live by in this culture; it structures the actions we perform in arguing" (p. 5).

Besides Argument is war, Lakoff and Johnson have documented many large-scale metaphoric systems in everyday language, such as Love is a journey, Ideas are food or Life is a container. A conceptual metaphor includes a source domain, from which we draw metaphorical expressions (war), and a target domain, which we try to understand (argument). The source-to-target interaction is called mapping.

Metaphors We Live By has initiated discussions and sparked important studies and debates among many cognitive scientists. As a linguist and a philosopher respectively, Lakoff and Johnson could not fully capture metaphor representation outside the field of cognitive linguistics. There are theoretical arguments against the conceptual metaphor theory, especially from cognitive psychologists such as Gentner or Murphy (1996). Murphy argues from a psychological point of view that Lakoff and Johnson do not provide a detailed psychological model of metaphor representation, and their model lacks a description of a process model for how such representations would be used in understanding and thought - aspects that are required in cognitive psychology (Murphy, 
1996, p. 176).

However, the conceptual metaphor model is widely accepted and often cited. The theory that language users think metaphorically is intuitively appealing to most readers. The Hungarian scholar Zoltán Kövecses has been greatly influenced by it. In turn, the universality of metaphors is not an entirely new conception. Nietzsche posited the same assumption in his essay On Truth and Lies in a Nonmoral Sense-that is, that concepts are metaphors. Before Lakoff, I. A. Richards also pointed out: "That metaphor is the omnipresent principle of language can be shown by mere observation. We cannot get through three sentences of ordinary fluid discourse without it ...” (Richards, 1936).

The 1980s saw renewed interest in the Sapir-Whorf hypothesis on linguistic relativity. According to this hypothesis, "an individual's thoughts and actions are determined by the language or languages that individual speaks" (Gippert, 2014). Lakoff and Johnson's theory was greatly influenced by linguistic relativity; they argue that languages use different cultural metaphors that reveal something about how users of a particular language think. In Metaphors We Live By, Lakoff and Johnson (1980) mention that their observations on how a language can reflect the conceptual system of its speakers derive in large part from the work of Edward Sapir and Benjamin Lee Whorf. Accordingly, a comparative analysis of metaphors related to the same concept across different cultures would demonstrate both differences and similarities in conceptualization by language users. Some metaphors are common to most cultures because they are based on general human experience. Connecting good with up and bad with down is an example of a common cultural feature. To test the assumption that specific metaphors might vary between cultures, some common English metaphors and their Hungarian counterparts will be analyzed according to cognitive views in a contrastive manner. 


\section{Comparison of English and Hungarian Metaphors}

Since the 1980s cognitive linguists have emphasized the importance of the universal aspects of metaphor. Lakoff stresses the importance of the concepts we live by and the conceptual system, which is metaphorical in nature. However, the number of cross-cultural studies dealing with the nonuniversalities has been less significant.

In spite of the universalities, metaphors can vary from culture to culture for various reasons. Native speakers' past experience is one of the most important aspects. An isolated culture that, for instance, has never encountered any cats would probably lack metaphors related to them. There are also source-target mapping variations and unique language peculiarities.

The most frequent sources from which metaphors are created are the things, which surround people in their daily lives. Such figurative expressions are related to weather, animals, plants, colors, and human body parts. In the case of human body parts and particularly the head, the metaphorical expressions are created based on various aspects, including the shape and the position of the head in relation to the rest of the body. Expressions like head of cabbage, head of state and headmaster work on the same principle. As I referred to it in the previous chapter good is usually connected with up in most cultures, therefore people in leading positions are a head of some institutions.

Kövecses (2005) points out that cognitive linguists and psychologists usually pose questions like "What is metaphor?" and "How does it work in the mind?" In contrast, anthropologists often ask, "What does metaphor do in particular social-cultural contexts?" (p. xi). In the following examples I elaborate on the latter issue. 


\subsection{Past Experiences}

Kövecses (2005) has examined several conceptual metaphors interculturally in his book Metaphor in Culture: Universality and Variation (p. 156). One of them is Love is a journey. This metaphor was introduced by Lakoff and Johnson (1980), who offered various metaphorical expressions for this conceptual metaphor.

For example:

(1) Look how far we've come.

Nézd/látod milyen messzire jutottunk.

(2) We'll just have to go our separate ways.

Elválnak útjaink.

The Hungarian equivalents seem to be straightforward translations, which are expressed in much the same way linguistically as in English. However, there are subtle differences in meaning. In the first sentence, come contrasts with jut. The Hungarian verb jut emphasizes the effort required to make progress in the relationship, whereas the English verb come is active and does not refer to difficulties in the progress. In the second example, two active agents are making a decision, whereas in Hungarian, an external condition (a fork) forces the agents to make a decision. Kövecses argues that such differences could be related to a more fatalistic attitude to life in the case of Hungarians. He has found that "[i]n several examples the American English sentences foreground active agents and deliberate action of these agents, as opposed to the foregrounding of a passive relationship and relative passivity of the people participating in the love relationship in Hungarian” (Kövecses, 2005, p. 158).

The experience of a nation greatly influences the way its people think and use metaphors. In 1991 the New York Times published an article entitled "Hungarians Are 
Thriving, Gloomily," which reported, "Poll after poll shows this nation to be the gloomiest in Eastern Europe-more unhappy and more fearful about the future than neighboring countries..." Prime Minister József Antall was also quoted: “A Hungarian will always see the worst. It comes in part from a peasant mentality, which will never predict a good harvest" (Bohlen, 1991).

The Prime Minister further mentioned that the motor of American life is optimism, but Hungarians tend to be pessimistic. The national anthem is inherently pessimistic as well. Hungarians also have a natural tendency toward melancholy and World Health Organization statistics reveal that this nation has one of the highest suicide rates in the world (WHO, 2009).

For this reason, it is not surprising that the so-called Suicide Song, "Gloomy Sunday," was composed by a Hungarian, the pianist and composer Rezső Seress. It became well-known during World War II in the United Kingdom and the United States after the release of a version by Billie Holiday. The original lyrics are depressing, but unlike Holiday's version, make no direct mention of committing suicide. The title can be considered a metaphor for loss, and the English lines maintained the impressive metaphor black coach of sorrow (bánatom hintaja), which is a key phrase in the tune. An urban legend alleges that many people committed suicide while listening to Gloomy Sunday. The fact is that Seress himself did commit suicide and the BBC banned the song; only instrumental versions were allowed on the radio. This inherently melancholic and pessimistic nature of Hungarians obviously reflects metaphor usage.

There are also metaphors that use the same source domains, but their meaning is different in the two cultures. For instance the metaphorical uses of blood in relation to certain emotions. An increase in blood temperature, as in boiling blood (forr a vére), is related to anger in English, but in Hungarian it is associated with someone who is 
passionate and eager to meet somebody. Furthermore, the metaphor in cold blood (hidegvérrel) has a negative connotation in English (unemotional person), whereas in Hungarian it conveys a positive meaning (someone who can be precise under pressure). The aforementioned examples indicate that the existence of the same metaphor in different cultures does not necessarily imply the same conceptualization. The meaning of figurative expressions is determined by the culture in which it is used.

\subsection{Source-target Mapping Variations}

Source-target mapping variations are also common in everyday language use. In this case, a different set of source domains conceptualizes a target. Greek to me refers to something that is not understandable. This metaphor was first used in English in

Shakespeare's play Julius Caesar. In the Hungarian version (Ez nekem kínai), instead of Greek, the source domain is China and it refers to the incomprehensible nature of the Chinese language. Not for all the tea in China works on the same principle. The Hungarian equivalent ( $A$ világ minden kincséért sem) makes use of a more general term (treasure) as the source domain. Numerous other metaphors related to the source domain tea are unique to British culture such as Not my cup of tea (Nem nekem való).

Many of the proverbial words of advice begin with Don't. Possibly one of the oldest is Don't count your chickens before they're hatched (Ne igyál elöre a medve börére). A variation of this metaphor can be found in most European cultures. This proverb first appeared in English in Thomas Howell's New Sonnets and Pretty Pamphlets (1570) as follows:

Counte not thy Chickens that vnhatched be, Waye wordes as winde, till thou finde certaintee... 
In Hungarian, the first recorded use of this metaphor is attributed to Péter Pázmány.

He coined the phrase in a letter to Péter Alvinczi:

Drágán árulja a medvebört, maga (noha) a medvéjét sem látta...

In the case of this metaphor as well, different source domains conceptualize the target. This pair of proverbs date back to almost the same time period, indicating that coining the equivalent metaphor works on the same principle in all cultures.

\subsection{Language Peculiarities}

There are also language peculiarities that have no equivalent in another culture. A person with gardening skills is said to have a green thumb in the United States and the corresponding British expression is green-fingered. However, in Hungarian there is no such expression related to gardening skills. Snake oil is a similar phrase in this regard. It refers to any kind of fraudulent health products or medicine. The origin of the phrase dates back to the mid 1800s when Chinese labourers gave snake oil to Europeans with joint pain.

Attila Cserép (2013) collected the metaphorical uses of horse in Hungarian and English. He mentions several metaphors that have no correspondence in Hungarian and vice versa. Among them are Horse of a different color, and You can lead a horse to water but you can't make him drink. There are also Hungarian horse metaphors without an English pair, for instance Elver valakit, mint szódás a lovát. The literal translation is: Beat somebody, like the soda-water carrier his horse.

Kövecses' idioms dictionary (2001) also lists several metaphors specific to English language. One of them is When in Rome. This phrase means that when someone visits another country, he/she should behave like the people in that country. A broader 
interpretation is to adapt yourself to the customs of the places you visit. This phrase does not have a related synonym in Hungarian using the same or different source domains.

In spite of the language peculiarities, most of the conventional metaphors work cross-culturally in English and Hungarian. The difference lies in the source domains which conceptualize the target domains. These two languages belong to different cultures of the world, without much contact with each other, although they share similar ways in conceptualization. For this reason, Lakoff and Johnson (1980) suggest that metaphors can vary from culture to culture and linguistic relativity seem to be appropriate as well. 


\section{Conclusion}

The purpose of this study was to present metaphors as an indispensable part of our everyday communication. Since antiquity, metaphor has been the most researched trope, and for this reason several theories of metaphor have been constructed. Aristotle considered it a privileged device, accessible only to creative people. However, Friedrich Nietzsche and other philosophers held that all language is metaphorical. Such diversities have characterized historically the development of metaphor.

The turning point was provided by the appearance of the cognitive science. During the process of rethinking the traditional philosophical views - which hold that metaphor is not a central concern in human perception of the world and metaphor comprehension is sequential—recent studies in cognitive linguistics have shown that metaphors are a fundamental part of human cognition. A classic experiment by Glucksberg also revealed that metaphor understanding is not optional and is processed as quickly and automatically as literal language. Metaphoric thinking does not require any special knowledge. Since the 1970s cognitive linguists and psychologists have become fully aware that metaphors are not only a matter of words, instead, as Lakoff suggests, metaphors are pervasive in thought, action and everyday language. In cognitive linguistics the importance of the universal aspects is also emphasized. By using examples from English and Hungarian, I have compared metaphors from the universal perspective and argued that metaphors in different cultures reflect a similar thinking pattern and languages may use different figurative expressions that reveal something about how users of a particular language think. Metaphoricity is a universal process. It occurs in all the languages of the world, in all strata of spoken and written communication; because human nature has been the same since the early days of humankind. 


\section{References}

Black, M. (1954). Metaphor. Proceedings of the Aristotelian Society, 55, 273-294.

Black, M. (1993). More about metaphor. In A. Ortony (Ed.), Metaphor and Thought (2nd ed.). Cambridge: Cambridge University Press.

Bohlen, C. (1991, June 24). Hungarians are thriving, gloomily. New York Times. http://www.nytimes.com

Bowdle, B. F., \& Gentner, D. (2005). The career of metaphor. Psychological Review, 112, 193-216.

Coulson, S., \& Van Petten, C. (2002). Conceptual integration and metaphor: An eventrelated potential study. Memory and Cognition, 30, 958-968.

Cserép, A. (2013). Metaphorical uses of horse in Hungarian and English. Argumentum, 9, $119-131$.

Davidson, D. (1984). Inquiries into truth and interpretation. Oxford: Clarendon Press.

Gentner, D. (1986). Evidence for a structure-mapping theory of analogy and metaphor. Tech. Rep. No. UIUCDCS-R-86-1316. Urbana: Dept. of Computer Science, University of Illinois at Urbana-Champaign

Gibbs, R. W., Jr. (1984). Literal meaning and psychological theory. Cognitive Science, 8, 575-304.

Gibbs, R. W., Jr. (2002). A new look at literal meaning in understanding what is said and implicated. Journal of Pragmatics, 34, 457-486.

Giora, R. (1997). Understanding figurative and literal language: The graded salience hypothesis. Cognitive Linguistics, 8, 183-206.

Gippert, J. The Sapir-Whorf Hypothesis. Retrieved April 23, 2014 from https://linguistlist.org/ask-ling/sapir.cfm

Glucksberg, S. (1998). Understanding Metaphors. Current Directions in Psychological Science, 7, 39-43.

Glucksberg, S., \& Keysar, B. (1993). How Metaphors Work. In A. Ortony (Ed.), Metaphor and Thought (2nd ed.). Cambridge: Cambridge University Press.

Glucksberg, S., Gildea, P., \& Bookin, H. A. (1982). On understanding nonliteral speech: Can people ignore metaphors? Journal of Verbal Learning and Verbal Behavior, 21, 85-98.

Keysar, B. (1989). On the functional equivalence of literal and metaphorical interpretations. Journal of Memory and Language, 28, 375-385. 
Kövecses, Z. (2001). English and Hungarian Idioms and Conversational Phrases. Budapest: Librotrade.

Kövecses, Z. (2005). Metaphor in culture: Universality and variation. Cambridge: Cambridge University Press.

Lai, V. T., Curran, T., \& Menn, L. (2009). Comprehending conventional and novel metaphors: An ERP study. Brain Research, 1284, 145-155.

Lakoff, G., \& Mark, J. (1980). Metaphors We Live By. Chicago: University of Chicago Press.

Metaphor. (n.d.) In Oxford Dictionaries online. Retrieved from http://www.oxforddictionaries.com/definition/english/metaphor?q=metaphor

Murphy, G. L. (1996). On metaphoric representation. Cognition, 60, 173-204.

Ortony, A. (1979). Beyond literal similarity. Psychological Review, 86, 161-180.

Ortony, A. (Ed.). (1993). Metaphor and Thought (2nd ed.). Cambridge: Cambridge University Press.

Richards, I. A. (1936). The Philosophy of Rhetoric. London: Oxford University Press.

Rosch, E. (1973). On the internal structure of perceptual and semantic categories. In T.E. Moore (Ed.), Cognitive development and the acquisition of language. New York: Academic Press, 111-144.

Searle, J. R. (1979). Metaphor. In A. Ortony (Ed.), Metaphor and Thought. Cambridge: Cambridge University Press.

Searle, J. R. (1983). Intentionality, an essay in the philosophy of mind. Cambridge: Cambridge University Press.

Shibles, W. A. (1971). An analysis of metaphor in the light of W. M. Urban's theories. The Hague: Mouton.

Wolff, P., \& Gentner, D. (2011). Structure-Mapping in Metaphor Comprehension. Cognitive Science, 35, 1456-1488.

World Health Organization (2009) "Suicide rates (per 100,000), by gender, Hungary, 1955-2009.” Retrieved from http://www.who.int/mental_health/media/hung.pdf 